\title{
Ethics in Ethnobiology Publication
}

James R. Welch

Author address: Escola Nacional de Saúde Pública, Fundação Oswaldo Cruz, Rua Leopoldo Bulhões 1480, Rio de Janeiro, 21041-210, Brazil

welch@ensp.fiocruz.br

Received: September 24, 2012

Volume: 3:96-97

Published: December 29, 2012

(C) 2012 Society of Ethnobiology

With the recent multiplication of traditional and electronic venues for publishing in ethnobiology, the social sciences, the life sciences, and related fields, it is increasingly important that authors practice selfdiligence to ensure that the contents of their publications meet criteria of veracity and ethical soundness. Although the peer-review process encourages high standards, it is an insufficient means for verifying the ethical worthiness of most publications. The ethical merits of published research derive from a cumulative process including formulating a research design, obtaining permissions, collecting and analyzing data, and finally composing and submitting a manuscript. Unfortunately, there is no failsafe ethical gatekeeper at any stage of the process. The importance of ethical publishing is all the more important in the field of ethnobiology, as professionals in the field often cross the intellectual and methodological boundaries between disciplines, and their research often involves multiple stakeholders in widespread jurisdictions.

There are good resources providing ethical guidelines for ethnobiology researchers and authors. For example, in 2006, the Society of Ethnobiology adopted the International Society of Ethnobiology (ISE) code of ethics (http://ethnobiology.net/codeof-ethics/) and additional resources are available on the Society's website (https://ethnobiology.org/ about-society-ethnobiology/ethics). Also, ethnobiological ethics are addressed in recently published chapters (Gilmore and Eshbaugh 2011; Hardison and Bannister 2011). These documents cover a broad range of topics and should be considered required reading for novice and experienced researchers alike. An important conclusion to be drawn from these sources is that ethnobiology research and publishing ethics cannot be reduced to any single issue and often vary according to the circumstances of a particular study. Whereas these documents emphasize ethical concerns as they relate to the subjects of research, publication involves additional obligations, such as those owed to the public.

Ethical publication is the responsibility of authors and publishers. In 2012, Ethnobiology Letters adopted a Publication Ethics and Malpractice Statement (http:// ethnobiology.org/publications/ethnobiology-letters), which outlines some of the responsibilities of authors, reviewers, and editorial board members. One of the most evident issues the statement identifies is disclosure by all parties of originality, conflicts of interest, and ethical soundness. As elementary as the idea of disclosure might appear, it can become more complex when put into practice. One of the most important factors involved in disclosure is straightforwardly providing all information that might be relevant for the readership to interpret and evaluate the merits of a study.

Ethical transparency in publishing includes but is not limited to disclosure that the minimum legal and institutional prerequisites for research were satisfied. In the United States, one such prerequisite is to obtain and adhere to IRB approval. However, especially in international settings, authorization may be required by multiple governmental agencies or community organizations. For example, in Brazil, current federal legislation requires that researchers obtain formal permission from government institutions to study traditional knowledge of biodiversity, to collect biological samples of any kind, to enter federal indigenous reserves, and to excavate archaeological sites on public and private land. Additionally, many indigenous and traditional communities in Brazil have their own leadership structures and associations that should be consulted for research authorizations. In some countries and academic fields, disclosure of permissions is standard practice and considered a necessary component of responsible publishing. Some 
authors, reviewers, and editors may not be aware of all the accepted norms in countries other than their own. At Ethnobiology Letters, we have adopted the practice of requiring authors to declare which permissions were obtained.

Of course, additional steps are often required to satisfy the requirements of informed consent and for the use of such information as intellectual property, artistic expressions, photographic images, and databases. Also, the publication of sensitive or confidential information, including the names of individuals, must be done with extreme care. Ultimately, the decision to publish specific information falls to the authors of an article and cannot be policed by any editorial board or scholarly organization.

One potential measure for ensuring that the contents of a publication are consistent with any applicable ethical constraints is consultation with local academic authorities, community representatives, or stakeholders. In some cases, it may be appropriate to involve advisors or research consultants as reviewers before submitting an article. As the ISE code of ethics emphasizes, due credit to research consultants is a standard of ethical research in ethnobiology. However, care must be taken because just as the failure to include material contributors as authors is widely regarded as a breach of publication ethics, so is the inclusion of people who did not take part substantially in the conception or execution of a study or reporting of its results ("gift authorship"). More information on ethical authorship and co-authorship is available from the Council of Science Editors (http:// www.councilscienceeditors.org).
Certainly, researchers must attend to ethical standards at every step beginning with the formulation of a research idea and continuing into the field or laboratory. However, the moment authors submit an article for publication many of the cumulative effects of unethical research become concrete in the eyes of the public. Once an article is published, the effects are difficult to undo through retraction. The ethical complexities involved in ethnobiology are diverse and open to interpretation, but they exist through efforts to ensure that our work benefits society. As part of that endeavor, responsible publishing is the concern of each and every one of us.

\section{References Cited}

Hardison P. and K. Bannister. 2011. Ethics in Ethnobiology: History, International Law and Policy, and Contemporary Issues. In Ethnobiology, edited by E. N. Anderson, D. M. Pearsall, E. S. Hunn, and N. J. Turner, pp. 27-49. John Wiley \& Sons, Hoboken, NJ.

Gilmore M. P. and Eshbaugh W. H. 2011. From

Researcher to Partner: Ethical Challenges and Issues Facing the Ethnobiological Researcher. In Ethnobiol$\circ g y$, edited by E. N. Anderson, D. M. Pearsall, E. S. Hunn, and N. J. Turner, pp. 51-63. John Wiley \& Sons, Hoboken, NJ.

\section{Biosketch}

James R. Welch is co-editor of Ethnobiology Letters and assistant professor of human ecology and health at the National School of Public Health in Rio de Janeiro. His research focuses on indigenous peoples in Brazil and California. 